\title{
Correction to: Integrative Nanomedicine for New Therapies
}

\author{
Anand Krishnan and Anil Chuturgoon
}

\section{Correction to:}

\section{A. Krishnan and A. Chuturgoon (eds.), \\ Integrative Nanomedicine for New Therapies, Engineering Materials, https://doi.org/10.1007/978-3-030-36260-7}

This book was inadvertently published with the incorrect Book Editor affiliation.

The "About the Editors" information has been updated. One of the co-authors "Bilal A AL Jaidi" name has been corrected as "Bilal A Al Jaidi" in the Chapter "Nanomedicines in Tuberculosis: Diagnosis, Therapy and Nanodrug Delivery".

The book and the chapter have been updated with the changes.

The updated version of the book can be found at https://doi.org/10.1007/978-3-030-36260-7

https://doi.org/10.1007/978-3-030-36260-7_13

A. Krishnan and A. Chuturgoon (eds.), Integrative Nanomedicine for New Therapies, Engineering Materials, 